\title{
Gestão do conhecimento como sistema de gestão para o setor público
}

\author{
Espartaco Madureira Coelho
}

\section{Introdução}

Durante a última década, a literatura tem apresentado vasto material que incita à reflexão e à discussão sobre a teoria organizacional, sendo que, nesta área, diversos autores têm demonstrado a importância do entendimento e da implementação dos conceitos, princípios, modelos e ferramentas de gestão do conhecimento como um novo paradigma para a boa gestão e o sucesso das organizações.

Paralelamente a esta abordagem teórica e/ou acadêmica, inúmeras foram as empresas desenvolvedoras de software que comercializaram soluções empíricas (plataformas e sistemas informacionais), ${ }^{1}$ com o objetivo de proporcionar o adequado suporte tecnológico à implantação de soluções de gestão do conhecimento por parte das organizações.

Entretanto, salvo as honrosas exceções que comprovam a regra, este novo modelo de gestão tem provocado pouco eco no âmbito das organizações públicas brasileiras e, quando encontra um lócus adequado, tem recebido um tratamento indevido, tanto em termos de difusão de seus pressupostos e da articulação de seus interlocutores quanto em relação ao nível de profundidade dos temas tratados.

Apesar de Adorno e Horkheiner (1985, p. 114) já afirmarem, na década de 80 , que "a racionalidade técnica é a racionalidade da própria dominação. Ela é o caráter compulsivo da sociedade alienada em si mesma", a importância da gestão do conhecimento, como fator de sucesso das organizações e da reprodução do capital, já é evidenciado desde o início dos anos 90, quando Drucker (1993, p. 15) assinala que "hoje o recurso realmente controlador, o fator de produção absolutamente decisivo, não é o

Espartaco Madureira Coelho é MBA em Planejamento, Orçamento e Gestão Pública pela FGV/DF, Especialista em Políticas Públicas e Gestão Governamental e assessor de TI da SecretariaExecutiva do Ministério da Educação.

Contato: espartac@msn.com 
capital, a terra ou a mão-de-obra. É o conhecimento”. O autor também afirma que "hoje o valor é criado pela produtividade e pela inovação, que são aplicações do conhecimento ao trabalho (ibidem, p. 16). Nesta obra, Drucker cunhou o termo "sociedade do conhecimento", que entendia ser de emprego ainda "prematuro (e certamente presunçoso)", mas que certamente já vivenciávamos uma "sociedade pós-industrial".

Nessa mesma linha de raciocínio, Castells (1999) também anunciou a superação da sociedade industrial afirmando que "uma revolução tecnológica concentrada nas tecnologias da informação está remodelando a base material da sociedade em ritmo acelerado" (ibidem, p.21) e que "a revolução da tecnologia da informação foi essencial para a implementação de um importante processo de reestruturação do sistema capitalista a partir da década de 80” (ibidem, p. 31).

O autor emprega os termos "sociedade pós-industrial" e "sociedade informacional" (ibidem, p. 32) e afirma que, "no novo modo informacional de desenvolvimento, a fonte de produtividade acha-se na tecnologia de geração de conhecimentos, de processamento de informações e de comunicação de símbolos. Contudo, o que é específico ao modo informacional de desenvolvimento é a ação de conhecimentos sobre os próprios conhecimentos como principal fonte de produtividade" (ibidem, p. 35).

\section{Conceitos básicos}

\section{Dados, informações e conhecimento}

Para obter-se um melhor entendimento do que venha a ser gestão do conhecimento, assim como para que seja possível aprofundar questões relacionadas aos processos de aprendizagem organizacional e ao emprego de tecnologias da informação, é apresentada uma descrição dos conceitos de dados, informações e conhecimento.

Conforme Davenport e Prusak (1998, p. 2), “dados são um conjunto de fatos distintos e objetivos, relativos a eventos", sendo que, "em um contexto organizacional, dados são utilitariamente descritos como registros estruturados de transações". Os "dados nada dizem sobre a própria importância ou relevância. Porém, os dados são importantes para as organizações - em grande medida, certamente, porque são matéria-prima essencial para a criação de informação" (ibidem, p. 3).

Informações "são dados interpretados, dotados de relevância e propósito” (Drucker, 1999, p. 32). De forma complementar, Senge (1999, p. 487) afirma que "informações são dados com relevância à situação do receptor", demonstrando "o importante papel do ser humano ao converter dados em informações”. Segundo Davenport e Prusak (1998, p. 4), 
"informação visa a modelar a pessoa que a recebe no sentido de fazer alguma diferença em sua perspectiva ou insight".

De forma contrastante ao termo "gestão do conhecimento", contrapõe-se o conceito de "gestão da informação", que está intrinsecamente associado à expressão "tecnologia da informação", proveniente da área de "processamento eletrônico de dados" que, por sua vez, refere-se às ferramentas, metodologias e técnicas utilizadas para a coleta, o armazenamento, o processamento, a classificação e a utilização de dados. Como hoje em dia as tecnologias da informação não podem ser dissociadas das tecnologias de comunicação (melhor seria dizer, das telecomunicações), temos o surgimento da expressão Tecnologias da Informação e das Comunicações, e a conseqüiente criação do acrônimo TIC.

Assim como a informação provém dos dados, o conhecimento deriva das informações. Da mesma forma, Davenport e Prusak (1998, p. 5) afirmam que os "dados tornam-se informação, quando o seu criador lhes acrescenta significado", sendo que este significado pode ser agregado por meio de cinco processos:

a) contextualização;

b) categorização;

c) cálculo;

d) correção; e

e) condensação.

Estes autores também afirmam que "para que a informação se transforme em conhecimento, os seres humanos precisam fazer todo o trabalho" (ibidem, p. 7), isto é, esta transformação vai agregar valor à informação, por meio de quatro processos:

a) comparação;

b) conseqüências;

c) conexões; e

d) conversação.

Assim, Davenport e Prusak concluem que "o conhecimento pode e deve ser avaliado pelas decisões ou tomadas de ação, às quais ele leva" (ibidem, p. 7).

Para Senge, (1999, p. 487) conhecimento é "a capacidade para a ação eficaz" e este "conhecimento somente se difunde quando existem processos de aprendizagem pelos quais os seres humanos desenvolvem novas capacidades de ação eficaz" (ibidem, p. 488) ou, como diz Humberto Maturama (apud Senge, 1999, p. 488): “Todo conhecer é fazer. Todo fazer é conhecer".

Por sua vez, Nonaka e Takeuchi (1997, p. 63) afirmam que:

a) "o conhecimento, ao contrário da informação, diz respeito a crenças e compromissos. O conhecimento é uma função de uma atitude, perspectiva ou intenção específica"; 
b) "o conhecimento, ao contrário da informação, está relacionado à ação." É sempre um conhecimento "com algum fim"; e

c) "o conhecimento, como a informação, diz respeito ao significado. É específico ao contexto e é relacional.”

De modo a dar maior clareza aos processos de criação de conhecimento, de geração de inovações, bem como para prover subsídios aos processos de aprendizagem organizacional, a partir da distinção entre conhecimento tácito e conhecimento explícito criada por Michael Polanyi (apud Nonaka e Takeuchi, 1997, p. 65), os autores desenvolvem uma teoria sobre as características e a complementaridade destes dois tipos de conhecimento, onde afirmam que o "modelo dinâmico da criação do conhecimento está ancorado no pressuposto crítico de que o conhecimento humano é criado e expandido pela interação social entre o conhecimento tácito e o conhecimento explícito" (ibidem, p. 67).

A este processo de interação e de "conversão do conhecimento", os autores postulam a existência de quatro modos de conversão do conhecimento (ibidem, p. 68):

a) socialização, que seria a conversão de conhecimento tácito em conhecimento tácito;

b) externalização, a conversão de conhecimento tácito em explícito;

c) combinação, a conversão de conhecimento explícito em conhecimento explícito; e

d) internalização, de conhecimento explícito para conhecimento tácito.

De posse destes modos de conversão do conhecimento, os autores afirmam que "a criação do conhecimento organizacional é uma interação contínua e dinâmica entre o conhecimento tácito e o conhecimento explícito".

Assim, é dada origem à expressão "espiral do conhecimento", processo em que "essa interação é moldada pelas mudanças entre os diferentes modos de conversão do conhecimento que, por sua vez, são induzidos por vários fatores" (ibidem, p. 79-80):

a) campo de interação;

b) diálogo ou reflexão coletiva;

c) associação do conhecimento; e

d) aprender fazendo.

A estes modos e fatores de transformação do conhecimento, os autores acrescentam os quatro conteúdos do conhecimento (ibidem, p. 81):

a) conhecimento compartilhado;

b) conhecimento conceitual;

c) conhecimento sistêmico; e

d) conhecimento operacional. 
Assim, o processo de conhecimento organizacional pode ser visualizado como uma espiral de criação do conhecimento, onde a organização possui a função de "fornecer o contexto apropriado para a facilitação das atividades em grupo e para a criação e o acúmulo de conhecimento em nível individual" (ibidem, p. 83).

\section{Gestão do conhecimento}

A expressão "gestão do conhecimento" ainda provoca um intenso debate sobre o seu significado, aplicação e abrangência. Entretanto, todos os estudiosos dos sistemas, práticas e modelos associados à gestão organizacional reconhecem o seu potencial e, simultaneamente, a sua natureza complexa, multidimensional e evolutiva.

Dizendo, assim, somos levados a pensar que os processos de gestão do conhecimento são atividades recentes, mas veremos que não o são. Segundo Klein (1998, p. 187), "o processo de aprendizagem organizacional" pode ser identificado como "um modelo de três estágios":

a) aquisição;

b) compartilhamento; e

c) utilização do conhecimento.

E estes estágios ou fases, mesmo que de formas distintas, já são praticados desde o início da humanidade, tanto pelas organizações civis, religiosas ou militares quanto pelas sociedades, mesmo antes do surgimento da escrita.

Conforme Lévy (1993, p. 75), são três as etapas do processo de difusão do conhecimento: a) oralidade (primária e secundária); b) escrita; e c) informática. Entretanto, ao vislumbrarmos que a informática é apenas uma das possíveis categorias de expressão das formas escrita e oral, podemos argumentar que, na história da humanidade, os processos de gestão e de difusão do conhecimento devem ser subdivididos, não apenas em três, mas em quatro grandes dimensões: a) da oralidade; b) da escrita; c) da impressão; e d) da informática; sendo que estas etapas podem ser complementares, umas às outras, e possuem patamares de complexidade, intensidade e abrangência cada vez maiores.

Como é de notório saber, as antigas civilizações surgiram com o advento dos sistemas de escrita cuneiforme (na antiga Mesopotâmia) e hieroglífica (no Egito e nas regiões habitadas pelos maias), momentos em que diversas informações sobre as atividades humanas puderam ser registradas, compartilhadas e utilizadas. Em 5.000 a.C. os sumérios criaram um calendário parecido com o que utilizamos atualmente (com 12 meses, de 30 dias cada um, e com um ano de 365 dias). Aproximadamente em 1.800 a.C, o Código de Leis de Hamurábi já consolidava a jurisprudência da época sobre questões relacionadas ao comércio e aos contratos, 
à família, à propriedade, ao trabalho, aos direitos e deveres dos estamentos sociais, bem como adotava penalidades baseadas na "Lei do Talião".2

Porém, antes do surgimento da escrita, já existiam as pinturas rupestres e inúmeros conhecimentos (sobre como preservar o fogo, plantar e colher, fazer ferramentas e armas com ponta de sílex, construir uma roda etc.), assim como, já existiam os rudimentos das atuais formas de transmissão e de reutilização de conhecimentos, seja por meio da manutenção das tradições orais ou pela memorização de "textos religiosos", o que tornou possível a preservação e a difusão, não só de informações e conhecimentos, mas de uma variedade de patrimônios e identidades culturais.

Durante o século 15 houve a invenção da tipografia (a impressão com caracteres móveis, criada por Johannes Gensfleisch Gutenberg), ${ }^{3}$ que, casualmente, proporcionou o sucesso do protestantismo, à época, mas que, principalmente, permitiu a popularização dos jornais (importantes veículos difusores de informações, formadores de opinião e de cidadania, mas também utilizados como instrumentos de propaganda e de manipulação política), dos livros e da leitura, ou seja, ocasionou uma verdadeira revolução na formas e na velocidade com que eram transmitidas idéias, informações e conhecimentos.

Mais recentemente, as invenções do rádio (Guglielmo Marconi, em 1874), do telefone (Alexander Graham Bell, em 1876) e da televisão (John Logie Baird, em 1925), cujos efeitos foram alavancados com o advento das redes mundiais de telecomunicações, fizeram com que a humanidade experimentasse as maiores transformações nas formas de apropriação dos materiais cognitivos e simbólicos criados pelos distintos grupamentos humanos.

Atualmente, impulsionada pela utilização do computador eletrônico (inventado por John Mauchly, em 1946) ${ }^{4}$, vivenciamos uma intensa proliferação de aplicações e de usos das TIC, que consolidaram a idéia da "instantaneidade das atividades humanas", ou seja, da capacidade de propagação e de utilização "em tempo real" de idéias e conhecimentos, tanto na busca de informações como no aprendizado e nos resultados obtidos, seja por indivíduos, por organizações ou por sociedades inteiras.

Então, a "gestão do conhecimento" é uma prática e um conceito já muito antigo que só agora foi guindado à situação de paradigma para a gestão de empresas e de organizações públicas?

Conforme Terra (2001, p. 245), a "gestão do conhecimento é, em seu significado atual, um esforço para fazer com que o conhecimento de uma organização esteja disponível para aqueles que dele necessitem dentro dela, quando isso se faça necessário, onde isso se faça necessário e na forma como se faça necessário, com o objetivo de aumentar o desempenho humano e organizacional". 
De acordo com Terra (2002, p. 57), "a gestão do conhecimento pode ser considerada o esforço para melhorar o desempenho humano e organizacional, por meio da facilitação de conexões significativas", sendo que também pode ser entendida como "um processo dinâmico, social que envolve mudanças contínuas nas habilidades e na aquisição de knowhow" (ibidem, p.63).

Por ser precursor das discussões sobre o tema, Klein (1998) trabalha com o conceito de "gestão do capital intelectual" e com o axioma de que "as organizações competem crescentemente com base em seus ativos intelectuais", no qual o conhecimento passou a ser considerado o principal fator de produção das modernas economias e a competitividade é determinada pelo "capital intelectual das empresas - seu conhecimento, experiência, especialização e diversos ativos intangíveis, ao invés do capital tangível, físico e financeiro" - e pelas inovações que as organizações conseguem gerar e difundir. Por ser "fonte essencial de vantagem competitiva", o capital intelectual "deve ser gerido de forma mais sistemática", de forma que "a estratégia da empresa para a gestão do capital intelectual... (seja)... incorporada a um portfolio de iniciativas gerenciais e tecnológicas no nível operacional".

De forma similar às definições acima, Davenport e Prusak (1998, p. XIV) afirmam que, em 1994, "Peter Drucker já havia identificado o conhecimento como a nova base da concorrência na sociedade pós-capitalista e Paul Bromer, economista de Stanford, denominou o conhecimento como o único recurso ilimitado, o ativo que aumenta com o uso". E ao constatarem que cada vez mais se fala do "conhecimento como o principal ativo das organizações e como a chave da vantagem competitiva sustentável”, propõem "que a única vantagem sustentável que uma empresa tem é aquilo que ela coletivamente sabe, a eficiência com que ela usa o que sabe e a prontidão com que ela adquire e usa novos conhecimentos".

Davenport e Prusak (1998, p. 61), de forma similar a Klein, também afirmam que o processo de gestão do conhecimento pode ser gerenciado e é composto por três etapas: a) geração; b) codificação; e c) transferência do conhecimento, sendo que na etapa de geração, podem existir "cinco modos de se gerar o conhecimento:

a) aquisição;

b) recursos dedicados;

c) fusão;

d) adaptação; e

e) rede de conhecimento" (ibidem, p. 64).

A etapa de codificação e de coordenação do conhecimento serve para "converter o conhecimento em formatos acessíveis e aplicáveis" à organização (ibidem, p. 93), é a etapa que "dá permanência para o conhecimento que, de outra forma, existiria apenas na mente das pessoas (ibidem, 
p. 106). E, na fase de transferência, ressaltam que, "embora o termo gestão do conhecimento implique a transferência formalizada, um de seus elementos essenciais é o desenvolvimento de estratégias específicas para incentivar essas trocas espontâneas"... "e não estruturadas do conhecimento" (ibidem, p. 108). Em relação ao uso de tecnologias, os autores aconselham que "a gestão do conhecimento eficaz só poderá ocorrer com a ampla mudança comportamental, cultural e organizacional" (ibidem, p. 170) e que "a mera presença da tecnologia não criará uma organização de aprendizado contínuo, uma meritocracia, nem uma empresa criadora de conhecimento" (ibidem, p. 171).

Fundamentalmente, assumindo uma abordagem sociológica no processo de análise das organizações (ressaltando a estrutura, os objetivos e o ambiente organizacional, em contraste com uma abordagem psicológicosocial, onde é dada ênfase nos problemas de liderança e de relações humanas), os autores tentam transmitir a idéia de que a gestão do conhecimento nada mais é do que "uma boa gestão de sistemas de informação, uma gestão de mudança organizacional e boas práticas na gestão de recursos humanos" (ibidem, p. 196).

Conforme Nonaka e Takeuchi (1997), “o sucesso das empresas japonesas se deve a suas habilidades técnicas na criação do conhecimento organizacional", ou seja, "na capacidade que uma empresa tem de criar conhecimento, disseminá-lo na organização e incorporá-lo a produtos, serviços e sistemas" (ibidem, p. 12).

Os autores também detectaram que "um número crescente de estudiosos nas áreas de organização industrial, gerenciamento da tecnologia, estratégia gerencial e teoria organizacional começou a teorizar sobre a administração do conhecimento".

Nonaka e Takeuchi são considerados os pioneiros no estudo sobre a geração e o uso do conhecimento em empresas japonesas, sendo os criadores do modelo de criação do conhecimento organizacional, denominado de "Espiral do Conhecimento" (ibidem, p. 80), que constitui-se uma abordagem, baseada na tradição intelectual e filosófica do Japão, que valoriza e integra os vários tipos de conhecimentos, esclarecendo que a inovação e a criação de novos conhecimentos organizacionais derivam da transformação ou "conversão do conhecimento tácito em conhecimento explícito" (ibidem, p. 11).

Esta "espiral dinâmica" do processo de criação de conhecimento organizacional também "envolve a interação entre dois tipos de aprendizado": o aprendizado de circuito simples (know-how, de Bateson, 1973) e o aprendizado de circuito duplo (know-why, de Argyris e Schön, 1978) (ibidem, p. 52).

Os autores ainda acreditam que o conhecimento e as inovações só são criados a partir da interação entre os dois tipos de conhecimento 
(estabelecidos por Michael Polanyi em 1966 (ibidem, p. 65)) e que existem "quatro modos diferentes de conversão do conhecimento:

a) de conhecimento tácito em conhecimento tácito, que chamamos de socialização;

b) de conhecimento tácito em conhecimento explícito, que denominamos externalização;

c) de conhecimento explícito em conhecimento explícito, ou combinação; e

d) de conhecimento explícito para conhecimento tácito, ou internalização" (ibidem, p. 68).

Da "espiral do conhecimento", os autores conceituam os "conteúdos do conhecimento" (ibidem, p. 81), criados pelos quatro modos de conversão do conhecimento e, a partir desta visão, sistematizam uma "espiral de criação do conhecimento organizacional" (ibidem, p. 82), que possui "cinco condições capacitadoras" (ibidem, p. 83), sendo que, como síntese, apresentam um "modelo integrado de cinco fases do processo de criação do conhecimento organizacional", que "deve ser interpretado como exemplo ideal do processo de criação do conhecimento" (ibidem, p. 95).

Este sistema aberto "ilustra que, para que a criação de conhecimento perdure, as condições capacitadoras devem ser aprimoradas ou atualizadas continuamente" (ibidem, p. 136), e que, para serem bem-sucedidos, os processos de gestão do conhecimento devem entender que a inovação contínua passa pela "atualização contínua dos valores organizacionais" e pela adoção de um "estilo gerencial e de estruturas organizacionais mais condutivas à criação do conhecimento organizacional”, como são os modelos "middle-up-down e hipertexto, respectivamente" (ibidem, p. 140).

Finalmente, os autores propõem a criação de um novo "modelo universal de gerência que reúna as práticas gerenciais encontradas no Japão e no Ocidente" (ibidem, p. 261), apresentando um conjunto de "recomendações" práticas e teóricas para auxiliar na implementação de projetos de criação de conhecimento, de inovação organizacional e deste novo modelo gerencial universal.

Conforme Senge (1999), que é o criador do conceito de "learning organization", de forma a manterem-se inovadoras e competitivas, as organizações deveriam transformar-se em “organizações que aprendem”, pois só estas possuem a capacidade de aprendizado gerativo e de aprendizado adaptativo, de modo a exercitarem a sua competência e inteligência coletiva para responder ao ambiente interno e externo.

"Nas organizações que aprendem as pessoas expandem continuamente sua capacidade de criar resultados que elas realmente desejam, onde maneiras novas e expansivas de pensar são encorajadas, onde a aspiração coletiva é livre, e onde as pessoas estão constantemente aprendendo a aprender coletivamente" (ibidem, p. 21). 
Para o autor, a aprendizagem organizacional é o processo contínuo de detectar e corrigir erros, mas esta organização, que aprende e que gera conhecimento, deve passar por profundas mudanças e deve implantar um novo estilo gerencial baseado em cinco disciplinas:

a) adoção do "pensamento sistêmico";

b) estímulo ao "domínio pessoal" da vida dos indivíduos;

c) identificação e questionamento dos "modelos mentais";

d) desenvolvimento de uma "visão compartilhada"; e

e) promoção do "aprendizado em grupo".

Sendo que o "pensamento sistêmico" é a disciplina que integra as demais disciplinas e dá coerência e unicidade ao modelo, pois induz a mente a enxergar o todo a partir das partes.

Assim, podemos concluir, resumidamente, que a gestão do conhecimento é o processo que tenta assegurar que as atividades de uma organização sejam transformadas em novos conhecimentos, ou seja, em novos processos e em produtos ou soluções inovadoras.

$\mathrm{E}$, que, gestão do conhecimento também é um novo modelo de gerenciamento das organizações, focado na aprendizagem contínua, na estratégia da inovação e na geração de conhecimentos.

\section{Gestão do capital intelectual}

Gestão do capital intelectual é a capacidade de as organizações implementarem processos de criação contínua e de proporcionarem valor de qualidade superior, sendo composto, conforme modelo originalmente desenvolvido por Karl E. Sveiby (Stewart, 2002, p. 21), pela interação entre:

a) o capital humano, que diz respeito às pessoas, seu intelecto, seus conhecimentos e experiências;

b) o capital estrutural (ou organizacional), formado pelos processos, manuais, marcas, patentes, estruturas organizacionais, sistemas de informações e outros que dão suporte às atividades a serem desempenhadas; e

c) o capital em clientes (ou em relacionamento), que corresponde ao valor dos relacionamentos com os usuários, clientes, fornecedores e todos os demais interessados no sucesso de uma organização.

Em outras palavras, esta abordagem privilegia um aspecto da gestão do conhecimento que está associado à manutenção da memória organizacional, ou seja, ao mapeamento, à sistematização e à adequada disseminação do conhecimento. Esta manutenção dos conhecimentos e das práticas da organização pretende reduzir o retrabalho e a perda de conhecimentos inerentes às habilidades e às experiências dos indivíduos que compõem a força de trabalho de uma organização. 
Gestão de recursos humanos, gestão de pessoal e gestão de pessoas ainda são expressões largamente difundidas, mas estão associadas a organizações e sistemas tradicionais, onde os processos de capacitação e de treinamento não estão atrelados à obtenção de melhores resultados organizacionais e/ou à satisfação das pessoas.

No escopo da gestão do conhecimento, "gestão de competências" é a expressão utilizada para promover a integração entre as atitudes, as habilidades e os conhecimentos necessários para que as pessoas alcancem resultados diferenciados, além de haver uma maior responsabilidade pelo processo de aprendizagem, tanto por parte do gerente quanto dos colaboradores.

Se os conhecimentos, as habilidades e as experiências dos indivíduos que compõem uma organização são essenciais à melhoria do desempenho e à difusão de práticas inovadoras, as competências inerentes aos cargos devem ser identificadas e comparadas com aquelas competências existentes na força de trabalho, de modo que seja iniciado um processo de negociação entre gerentes e equipes, de forma a haver a compatibilização entre estas realidades e a superação ou redução dos diferenciais encontrados.

Assim, em uma organização que busca melhores níveis de desempenho, tornam-se preponderantes:

a) o desenvolvimento de um programa de capacitação que proporcione uma maior adequação ou que elimine os diferenciais existentes entre as competências desejadas (ideais) e as competências apresentadas (reais); e

b) a criação de um "banco de talentos", que permita identificar conhecimentos, habilidades e potenciais na equipe de colaboradores e, que também, possibilite estabelecer diretrizes para a alocação de pessoas aos grupos de trabalho (este tipo de atividade é, usualmente, denominado de "gestão de talentos").

\section{Aprendizagem contínua}

As constantes e rápidas mudanças nas tecnologias e nos desafios com que se deparam as organizações exigem competências e habilidades cada vez mais distintas dos trabalhadores e é consenso, atualmente, o fato de que o melhor profissional é aquele que "sabe aprender" ou que "está continuamente aprendendo".

Entretanto, conforme Senge (1998, p.44), a "disciplina" ou o processo de "aprendizagem em equipe é vital, pois as equipes, e não os indivíduos, são a unidade de aprendizagem fundamental nas organizações 
modernas. Esse é um ponto crucial: se as equipes não tiverem capacidade de aprender, a organização não o terá”.

Desta forma, as organizações devem buscar soluções (integradas com o conceito de gestão de competências, apresentado acima) para o desenvolvimento de ferramentas e métodos de aprendizagem individuais e coletivas, e assumirem que a função ou a responsabilidade pelos processos de aprendizagem extrapola os departamentos de treinamento e de capacitação e torna-se um imperativo para as ações gerenciais das organizações modernas.

Hoje em dia as ferramentas mais utilizadas para o desenvolvimento de ações voltadas à aprendizagem contínua e à construção de um processo de educação organizacional estão baseadas na instituição das "Universidades Corporativas", assim como no uso intensivo das facilidades tecnológicas embutidas nas práticas de Ensino a Distância (EaD), no e-learning (via Internet), na disseminação de bases de dados com as "melhores práticas" (best practices) e as "lições aprendidas" (lessons learned), bem como no desenvolvimento de portais corporativos, onde o intercâmbio de informações e conhecimentos sirva como facilitador e catalisador de inovações e de geração de novos conhecimentos.

\section{Portais corporativos}

De forma distinta dos portais comerciais e de acesso à Internet, os portais de conhecimento corporativo são, segundo Terra (2002, p. 16), “a nova cola para dar apoio à transformação fundamental" nos atuais modelos organizacionais e naquelas atividades intensivas em conhecimento, assim como são os provedores de um ambiente tecnológico que permite a adequada gestão das informações e dos conhecimentos de uma organização.

De forma a serem reconhecidos como legítimos portais corporativos, e promoverem o aumento da capacidade de solução de problemas e/ou de geração de inovações no interior das organizações, estes devem atender a determinados objetivos específicos, quais sejam os de:

a) integrar o uso de aplicativos e bases de dados informatizadas;

b) conectar os indivíduos às fontes de informação, unificando os ambientes de pesquisa, organização e divulgação e/ou publicação das informações e do conhecimento necessário às organizações;

c) "permitir a personalização do acesso à informação;

d) automatizar e aperfeiçoar os ciclos de decisão dos trabalhadores do conhecimento;

e) permitir a criação de níveis mais profundos de colaboração entre os funcionários" (ibidem, p. 17); e

f) "fomentar a criação e a reutilização do conhecimento explícito e a localização de pessoas que podem aplicar seu conhecimento tácito em situações específicas" (ibidem, p. 51). 
Além disso, os portais corporativos, ao integrarem os fluxos de dados, informações e conhecimentos, também podem ser utilizados como ferramenta de apoio à mudança da cultura das organizações, incentivando a colaboração e o compartilhamento de experiências e conhecimentos, remodelando as formas de organização do trabalho e de capacitação, assim como redesenhando processos, atividades, relacionamentos, hierarquias e estruturas.

\section{Comunidades de prática}

$\mathrm{O}$ advento das redes de computadores e, principalmente, a consolidação da Internet permitiram a proliferação das chamadas "Comunidades de Prática" (CdP), ou seja, comunidades virtuais de colaboração voluntária, que, na verdade, nada mais são do que grupos de pessoas constituídos de maneira informal (isto é, independentemente das estruturas organizacionais às quais pertençam), em função da satisfação de interesses ou da solução de problemas comuns, seja para a troca de idéias, informações e experiências, seja para um tipo de aprendizado mais estruturado.

As CdP usam ferramentas especiais de groupware ou, mesmo, aquelas disponibilizadas para os grupos de discussão e para as comunidades virtuais gratuitas, como o compartilhamento de áreas de disco, o correio eletrônico, as salas de discussões, as votações eletrônicas, os murais on line, os e-zines, os blogs etc, para a troca de idéias, documentos, programas, informações, conhecimentos e experiências.

Conforme Terra (2002, p. 72), "o conceito de CdP foi originalmente cunhado por Etienne Wenger ${ }^{5}$ e é, atualmente, um dos temas mais promissores no campo da gestão do conhecimento. Comunidades de Prática é um termo que se refere às maneiras como as pessoas trabalham em conjunto e/ou se associam a outras naturalmente".

Atentas a estas constatações, as modernas organizações buscam formas de incentivar a criação de $\mathrm{CdP}$ focadas em produtos ou em processos organizacionais (podendo, inclusive, integrar clientes e fornecedores), de forma a propiciar um ambiente de inovação e de geração de conhecimentos, bem como para proporcionar uma maior transferência daqueles conhecimentos gerados dentro das $\mathrm{CdP}$ para o restante das organizações.

Entretanto, todos os estudos realizados têm demonstrado que, em geral, os colaboradores possuem uma resistência natural ao compartilhamento de conhecimentos e que os conhecimentos não fluem facilmente, mesmo quando as organizações realizam esforços consistentes e coordenados, no sentido de implementar projetos de gestão do conhecimento. 


\section{Desafios para a implantação de projetos de gestão do conhecimento no setor público}

\section{Considerações sobre um novo modelo de gestão do conhecimento}

Para Senge (1998, p.12), nas modernas organizações, "talvez a aprendizagem se tornará mais importante do que o controle" e, assim sendo, este será o principal foco de gestão das "organizações baseadas no conhecimento ou das organizações que aprendem: organizações inerentemente mais flexíveis, adaptáveis e mais capazes de se reinventarem".

Conforme definido anteriormente, "gestão do conhecimento também é um novo modelo de gerenciamento das organizações, focado na aprendizagem contínua, na estratégia da inovação e na geração de conhecimentos", só que, apesar das organizações públicas serem notadamente intensivas em conhecimento, a sociedade brasileira, em geral, e as três esferas da administração pública, de maneira genérica, não possuem uma cultura e um ambiente voltados para a aprendizagem organizacional e/ou para a inovação e, com raras exceções, também não incentivam a educação continuada de seus servidores.

Outros dois fatores que também são aplicáveis às organizações privadas, mas que podem ser somados a essa dimensão cultural, de forma a corroborarem a tese de que as organizações públicas enfrentam inúmeras resistências às mudanças e à efetiva implementação dos modelos e das ferramentas de gestão do conhecimento, foram explicitados pelo Centro Canadense para o Desenvolvimento da Gestão (CCMD, 2001, p.101), ao constatar que "o simples tamanho de várias organizações públicas torna difícil a administração de mudanças de forma abrangente. Além disso, ainda não está claramente definida a maneira de gerenciar o conhecimento e o "poder do intelecto", que são bem menos tangíveis do que outras características da vida organizacional".

Um elaborado levantamento das razões pelas quais as organizações "de todos os tipos" deveriam transformar-se em organizações de aprendizagem já foi apresentado pelo Centro Canadense para o Desenvolvimento da Gestão (CCMD, 2001, p. 105-108):

- “As novas tecnologias de informação e de comunicação possibilitam o acesso a uma enorme quantidade de informação e de dados. Os trabalhadores com capacidades intelectuais sofisticadas e com habilidades técnicas (i.e., "trabalhadores do conhecimento") são chamados a extrair o máximo que estas oportunidades proporcionam sem, no entanto, ficar sobrecarregados pela "carga excessiva de informação". Além disso, essas novas tecnologias estão 
acelerando o ritmo das mudanças e criando canais mais complicados

de interdependência entre as pessoas. Formas de organização mais flexíveis e mais responsáveis são necessárias para adaptar-se a este novo ambiente de trabalho de "conhecimento intensivo".

- As sociedades estão se tornando cada vez mais diversificadas, ou seja, diversificadas nos gostos pessoais, na herança étnicocultural, no estilo de vida, e na situação socioeconômica. Ao mesmo tempo, os cidadãos estão demandando uma maior adaptação de bens e serviços aos desejos e necessidades pessoais. Em todos os países industrialmente avançados, as instituições estão sendo forçadas a satisfazer estas expectativas mais altas dos cidadãos. Aquelas que falham nesse intuito tendem a sofrer uma perda de legitimidade e de autoridade. As instituições, (tais como as instituições políticas, os serviços públicos e as profissões bem estabelecidas), precisam refletir e alavancar esta diversificação para permanecer relevantes. Isto requer a habilidade de entender as questões de diferentes perspectivas, integrar as várias idéias dentro de um "grande quadro" coerente, e compor mensagens persuasivas para uma audiência diversificada.

- A natureza das relações dentro do espaço de trabalho mudou. As formas tradicionais de autoridade de comando e controle, e de microgerenciamento estão se mostrando ineficazes. Os gerentes delegam mais e deles é exigido um repertório de habilidades que incluem o coaching, o mentorato e a capacidade de negociação. Os empregados precisam de habilidades para trabalhar dentro de ambientes fluidos e baseados em equipes, ou dentro de arranjos completamente novos de trabalho (por exemplo, teletrabalho). $\mathrm{O}$ trabalho perpassa cada vez mais transversalmente a organização, necessitando de novas formas de diminuição de fronteiras nos relacionamentos profissionais. Todas estas mudanças têm criado um espaço de trabalho mais "horizontal" que precisa de novas competências e novas práticas organizacionais. Algumas atividades ficaram sobrecarregadas pelo novo ambiente e exigem habilidades para lidar com o estresse, a carga de trabalho, e o equilíbrio entre trabalho e a vida privada.

- É fato que os recursos intelectuais de uma organização se esgotam, a não ser que sejam constantemente revigorados. Em outras palavras, um empregador não pode esperar lealdade e capacidade auto-sustentável de um empregado se ele simplesmente "minar" o conhecimento e os talentos de sua força de trabalho. Estas tendências interligadas afetam organizações de todos os tipos, sejam elas 
do setor público, do setor privado, ou do terceiro setor (voluntárias e sem fins lucrativos). Existem, contudo, razões mais específicas para que o setor público necessite "aprender a aprender" mais efetivamente.

- Como sublinha Peter Aucoin, é necessário um serviço público altamente profissional para o estabelecimento de um bom governo, dentro de uma sociedade e de um sistema econômico cada vez mais complexos (Aucoin, 2000). O aprendizado está ficando cada vez mais crucial para a promoção do profissionalismo em, pelo menos, dois pontos. Primeiro, o profissionalismo é realçado por meio de investimentos ativos em conhecimento e em habilidades profissionais. Segundo, o conhecimento profissional pode ser compartilhado em uma base contínua, pelo estabelecimento de redes, tanto dentro de organizações quanto entre organizações, ou, inclusive, governos.

- Uma maior investigação está sendo implementada para que os governos sejam mais abertos, transparentes e responsáveis. Os cidadãos e a mídia demandam garantias mais concretas de que o serviço público está prestando serviços de alto valor. Isto quer dizer que as informações do governo precisam ser postas ao alcance dos cidadãos - por meio de novas tecnologias eletrônicas (governo eletrônico) e de um diálogo entre os servidores públicos e os cidadãos.

- As organizações públicas têm sido forçadas a encontrar maneiras de competir com o setor privado no recrutamento dos poucos talentos remanescentes. Por razões políticas, uma organização pública não pode oferecer salários extremamente altos e "incentivos" exorbitantes. Uma organização pública pode, por outro lado, estimular um sentimento de orgulho no serviço público e fazer investimentos ativos no desenvolvimento pessoal e profissional de um indivíduo. Em decorrência da sua ênfase histórica ao treinamento, as organizações públicas estão bem posicionadas para contribuir para com o crescimento intelectual do trabalhador e para com seu sentimento de realização pessoal.

- Vários serviços públicos em países avançados e industrializados estão enfrentando uma abertura na estrutura de idade de sua força de trabalho. A aposentadoria iminente da geração baby-boom, representada por várias décadas de medidas de austeridade fiscal, põe a capacidade existente de vários governos em risco. As organizações públicas precisam encontrar novas maneiras de preservar suas "memórias" organizacionais e treinar novas gerações para o serviço público. 
- As políticas públicas, cada vez mais, perpassam transversalmente as estruturas governamentais tradicionais, as jurisdições governamentais e as fronteiras nacionais. Por exemplo, questões ambientais têm relação com a política industrial, com a política de recursos naturais, com a política de desenvolvimento das exportações, com o turismo, com a proteção ambiental, e com o desenvolvimento urbano, para mencionar apenas algumas. As organizações públicas precisam encontrar melhores maneiras para trabalhar horizontalmente em uma base contínua - trocando informação e empenhando-se em colaborações significativas".

De forma diversa à do Canadá, as tentativas de adoção de qualquer "tecnologia de gestão" por parte do governo brasileiro, como a da gestão do conhecimento, por exemplo, devem atentar para a necessidade de serem tratadas, de forma estratégica, situações ou condicionantes associadas aos seguintes aspectos:

a) desprestígio dos serviços e dos servidores públicos junto à sociedade;

b) abandono das iniciativas de padronização e de melhoria dos procedimentos administrativos;

c) problemas éticos, legais e de legitimação associados à administração pública e ao Estado;

d) desequilíbrios entre cargos em comissão, contratações temporárias e quadro efetivo;

e) descontinuidade administrativa de objetivos, estruturas e projetos e de políticas públicas;

f) permanência de modelos, estilos e atitudes gerenciais inadequadas;

g) irracionalidade das diferenciadas estruturas de carreiras, cargos, salários e benefícios concedidos;

h) inadequação do quantitativo de pessoal e/ou dos níveis de capacitação e de motivação do corpo funcional;

i) falta de padrões de interoperabilidade e de adequação (quantitativa e qualitativa) da infra-estrutura de tecnologia da informação;

j) fragilidade do sistema de recompensas, reconhecimento e punições, voltado à melhoria do desempenho funcional e dos resultados organizacionais; e

k) coexistência de culturas e climas organizacionais impróprios à colaboração e ao compartilhamento de conhecimentos.

Diante destas considerações, é apresentada proposta para o desenvolvimento de um modelo de gestão do conhecimento, mais adequado às peculiaridades das organizações públicas brasileiras, baseado em cinco sistemas permanentes de gerenciamento: 
a) do planejamento estratégico;

b) da padronização de procedimentos;

c) do capital intelectual;

d) do ambiente de inovação; e

e) da aprendizagem contínua.

\section{Planejamento estratégico}

Conforme Carlos Matus (apud Huertas, 1996, p. 14), “o planejamento é um cálculo que precede e preside a ação para criar o futuro", ou seja, antes de qualquer organização adotar iniciativas ou políticas de gestão do conhecimento, esta deve conhecer os seus objetivos, os seus macroprocessos, as suas atividades, os seus produtos ou serviços, assim como os recursos humanos e materiais a serem alocados, pois sem esta visão sistêmica, nem a alta direção, nem o corpo funcional podem promover a convergência de esforços e de interesses, fazer uma boa gestão ou, mesmo, obter um desempenho satisfatório.

Adicionalmente, em função do Planejamento Estratégico Situacional - PES, de Carlos Matus, ser "um método e uma teoria do Planejamento Estratégico Público" (Huertas, 1996, p. 22) e estar fundamentado na "teoria das situações" e na "análise situacional" (ibidem, p. 29), este seria o paradigma mais adequado para permitir a monitoração e a análise de informações necessárias à tomada de decisão, e que estaria contemplando uma recomendação comum às organizações privadas, mas ainda incipiente nas organizações públicas, de adotarem uma ação gerencial no sentido de prover "inteligência empresarial” ou "inteligência competitiva", sempre que estas buscassem administrar e/ou gerir o seu conhecimento.

\section{Padronização de procedimentos}

Conforme Max Weber, apesar das disfunções há muito caracterizadas, as burocracias possuem aspectos positivos, baseando-se na divisão racional do trabalho, na formalidade e na legalidade de seus atos e na estrutura hierarquizada, de modo a obterem o máximo de eficiência. Entretanto, mesmo sabendo que as instituições públicas são atavicamente burocráticas, a atual crise administrativa não tem se restringido à descontinuidade de projetos, programas e políticas, às mudanças de diretrizes e à troca de ocupantes de cargos de confiança na alta administração a cada quatro anos, mas também em função do enfraquecimento das instituições e da função pública, em geral, os agentes políticos, não afeitos a teorias administrativas, modelos, técnicas e tecnologias de gestão, conduziram as organizações públicas a uma situação de inanição operativa, seja pelo contingenciamento de recursos, seja pela falta de estruturas mínimas de 
funcionamento, seja pela falta de preservação do conhecimento técnicoadministrativo e organizacional, o que transformou as organizações públicas em burocracias (agora plenas de significados negativos) prejudiciais ao fortalecimento da democracia e ao desenvolvimento econômico e social.

Neste sentido, de posse de um conjunto de informações geradas durante o planejamento estratégico situacional, como a missão, a visão, os objetivos estratégicos, a identificação dos seus macroprocessos e com o estabelecimento de procedimentos de avaliação do desempenho, as organizações públicas podem voltar a gerenciar os seus processos utilizando, por exemplo, o modelo de gestão do Programa de Qualidade do Serviço Público ou implantar as metodologias Six Sigma e Balanced Scorecard.

No caso de estas instituições optarem por ações de curto prazo, devem disseminar o método de gestão de processos baseado no ciclo PDCA de controle, promovendo a educação e a comunicação para todos os colaboradores e, assim, implementar infinitos ciclos de análise, de padronização (a chave para a previsibilidade da qualidade, dos custos e dos prazos dos serviços realizados) e de melhoria de seus processos e rotinas.

Conforme Falconi (1994), "não existe um método rígido de melhoria do gerenciamento" [pelas diretrizes ou de rotinas] (ibidem, p. 24), mas "não existe gerenciamento sem padronização" (ibidem, p. 31). Sendo que a garantia da qualidade dos serviços deve ser alcançada pela "prática do controle (ciclo PDCA)" (ibidem, p. 147), composta por três etapas: "a) definir seus padrões com base nas necessidades das pessoas; b) trabalhar conforme os padrões (manter); e c) melhorar constantemente os padrões para satisfação das pessoas" (ibidem, p. 148).

Após a reestruturação dos seus processos, atividades e tarefas, as organizações devem promover as devidas adaptações nas suas estruturas organizacionais, de forma a compatibilizar os processos de trabalho, os fluxos de comunicação e a hierarquia de poder, de competências e de responsabilidades, em relação aos objetivos organizacionais estabelecidos.

\section{Capital intelectual}

Assim como o planejamento estratégico e a análise, padronização e melhoria de processos, a gestão do capital intelectual - caracterizada, no item 1.3 deste trabalho, como a eficaz administração dos capitais humano, estrutural e de relacionamento - é considerada condição sine qua non para uma razoável gestão dos processos, dos resultados e dos recursos utilizados pelas organizações, pois esta competência está associada à manutenção da capacidade operativa e à preservação da memória organizacional, ou seja, proporciona o adequado mapeamento, a organização e a divulgação das informações e dos conhecimentos necessários à continuidade administrativa das organizações. 
Se a gestão do conhecimento propõe-se a ser um novo modelo de gestão para as organizações (privadas e/ou públicas), nada mais coerente do que pregar a existência de novas práticas gerenciais, de estruturas organizacionais diferenciadas e de formas de organização do trabalho inovadoras que viabilizem o desenvolvimento de uma cultura organizacional que favoreça a criação e a difusão de novos conhecimentos. E nada mais desafiador do que tratar da cultura e dos valores organizacionais, dentre os ativos intangíveis das organizações, talvez os menos considerados.

Neste sentido, Nonaka e Takeuchi (1997) propuseram o estilo gerencial, denominado middle-up-down, como o processo gerencial mais adequado, tanto para "estimular a interação dinâmica necessária à criação do conhecimento organizacional", como por considerarem-no "superior para a criação do conhecimento em relação aos modelos mais tradicionais" (ibidem, p. 141), a saber: a) hierárquico ou top-down (de cima para baixo), baseado na autoridade e na divisão do trabalho; e b) bottom-up (de baixo para cima), baseado em estruturas organizacionais mais horizontais e com maior autonomia para os indivíduos.

Nesse novo processo gerencial, denominado de middle-up-down, que se apropria da forma iterativa e espiral com que os conhecimentos são criados, os "gerentes de nível médio" - aqueles representantes da alta administração, que exercem funções táticas nas organizações e são os responsáveis pelo desenvolvimento das equipes de trabalho e pela adequada comunicação entre o topo (nível estratégico) e a base da estrutura organizacional (nível operacional) - são considerados, pelos autores, como "a chave para a inovação contínua", pois seriam "o centro da gestão do conhecimento", em função de estarem posicionados "na interseção dos fluxos vertical e horizontal de informações dentro da empresa" (ibidem, p. 145).

Contraditoriamente, a literatura usualmente considera que os gerentes de nível médio são os principais responsáveis pela elevada resistência às mudanças, à insuficiente delegação de competências e à inadequada comunicação entre os níveis estratégico e operacional das organizações - fundamentalmente, por temerem a perda de poder, de direitos e de privilégios - mas, exatamente, por serem o ponto nevrálgico destas questões é que devam ser considerados como "a chave para a inovação contínua”, ao viabilizarem a tradução dos conhecimentos implícitos, dos colaboradores e dos dirigentes, em conhecimentos explícitos e incorporando-os em novas tecnologias, produtos e/ou serviços.

Nonaka e Takeuchi (1997, p. 148) consideram que este modelo gerencial "é de longe o mais abrangente em termos de quem é envolvido; o mais inclusivo em termos de qual é o tipo de conhecimento criado; o 
mais amplo em termos de onde o conhecimento é armazenado; e o mais flexível em termos de como o conhecimento é criado".

Os autores também desenvolveram o conceito da "organização em hipertexto" como uma alternativa às estruturas hierárquicas tradicionais e às forças-tarefas (e, mesmo, às estruturas matriciais), que de forma coerente com a sua "espiral do conhecimento", "colhe benefícios de ambas", pois "a eficiência e estabilidade da burocracia aliam-se à eficácia e ao dinamismo da força-tarefa", além de "acrescentar outro nível, à base de conhecimento, que serve como "carteira de compensação" para o novo conhecimento gerado nos níveis de sistema de negócios e equipe de projeto" (ibidem, p. 197).

Em relação ao ambiente e à cultura organizacional, Senge (1999, p. 491) afirma que a capacidade de uma organização difundir práticas inovadoras depende, entre outros fatores, de "uma cultura organizacional que encoraje a reciprocidade, a curiosidade e a reflexão, além das fronteiras internas e externas e de infra-estruturas de aprendizagem (meios de organizar os recursos e oportunidades para promover reflexão e compartilhamento regulares)".

Em função de o compartilhamento do conhecimento só poder ser realizado de forma voluntária e depender intrinsecamente do grau de motivação e de confiança dos colaboradores, as organizações devem não somente disponibilizar ambientes e ferramentas tecnológicas, mas, principalmente, promover mudanças na sua cultura e nos seus valores organizacionais, com destaque para a reavaliação integrada dos seguintes aspectos:

a) grau de transparência e accountability da alta administração;

b) sistemas de punição e recompensa;

c) participação dos colaboradores nos diferentes fóruns de formulação e de decisão;

d) sistema de análise, padronização e melhoria de processos;

e) atitudes gerenciais;

f) sistemas de comunicação interna;

g) racionalidade das estruturas, dos cargos e dos salários; e

h) sistemáticas de avaliação de desempenho funcional e dos resultados organizacionais, entre outros.

\section{Aprendizagem contínua}

$\mathrm{Na}$ atual conjuntura nacional, existem poucos questionamentos às condições da exploração do trabalho e de apropriação da mais-valia, exceto em relação àquelas situações referentes ao trabalho escravo ou infantil, pois recentemente houve um "crescimento negativo" (sic) do nível de emprego e da renda do trabalhador. Neste caso, a famosa frase da 
economista inglesa Joan Robinson6: "só há uma coisa pior do que ser explorado (pelo imperialismo), é não ser por ele explorado", aborda a questão do desemprego de forma definitiva.

Assim, em um mundo de constantes mudanças, a máxima "não dê um peixe ao homem que tem fome, mas ensine-o a pescar" já foi assimilada há muito tempo, pois todos aqueles indivíduos que buscam melhores condições de emprego ou de inserção no mercado de trabalho precisam estar permanentemente atualizados, informados e capacitados, ou seja, devem "estar permanentemente aprendendo".

Hoje em dia, o fato de que todos devem estar imersos em processos de aprendizagem continuada já não é novidade, e a moderna literatura preocupa-se:

a) em assinalar que o grande desafio é o de que os indivíduos devam saber "aprender a aprender"; e

b) em resgatar a importância dos processos de learning by doing (consagrado pelo boom educacional, tecnológico e produtivo dos Tigres Asiáticos), que os atuais manuais denominam de "ênfase no treinamento em ação" (Stewart, 2002, p. 358).

Assim, as organizações públicas, que, por sua vez, já estão cientes destas verdades, devem desenvolver estratégias justas, inovadoras e democráticas, de forma a que os colaboradores possam estar permanente e continuamente aperfeiçoando suas habilidades e seus conhecimentos, sem incorrer em práticas paternalistas, mas sabendo compatibilizar uma adequada gestão de competências com o alcance dos resultados políticoinstitucionais esperados.

\section{Conclusão}

Apesar de as organizações públicas possuírem propósitos distintos das organizações privadas (para o setor público, a eficiência está associada ao atendimento das demandas da sociedade e, para o setor privado, a eficiência está vinculada a aspectos ligados à lucratividade dos empreendimentos), atualmente, as estratégias e as tecnologias utilizadas para a consecução de seus objetivos tendem a ser semelhantes, por isso este estudo busca suprir uma demanda relacionada à necessidade de a gestão do conhecimento ser mais analisada, compreendida e, conseqüentemente, melhor aproveitada pelas diferentes esferas do poder público.

Conforme apresentado neste trabalho, pode-se constatar a importância e a complexidade da gestão do conhecimento e a existência de um grande desafio para a implantação de projetos deste gênero no âmbito da administração pública brasileira, principalmente pelo predomínio de critérios políticos que moldaram um setor público carente de recursos e estruturas 
minimamente capazes de responderem aos seus desafios operacionais

básicos. E daí, a importância da gestão do conhecimento, como nova tecnologia de gestão a ser adaptada e plenamente usufruída para a melhoria de desempenho da função pública.

O modelo de gestão do conhecimento, aqui ajustado e proposto para o setor público, se bem utilizado, pode ser uma resposta eficiente para o enfrentamento de inúmeros problemas existentes e que, rapidamente, poderia elevar o padrão de gestão das organizações públicas, devido ao conseqüente "efeito catch-up" a ser obtido. Entre os economistas, este é o termo utilizado para explicar o fato de um pequeno investimento proporcionar elevadas variações nos níveis de produção e/ou desenvolvimento, em função do nível de produção e/ou desenvolvimento ser muito baixo ou quase nulo, ceteris paribus.

Deve-se esclarecer que as cinco dimensões do modelo de gestão apresentado deveriam constituir-se um núcleo mínimo de boas práticas organizacionais, que poderiam subsidiar o desenvolvimento de projetospiloto em gestão do conhecimento a serem implantados por qualquer organização.

Finalmente, segundo Lévy (2000, p. 159), além das questões práticas decorrentes das novas "tecnologias da inteligência", também devem ser discutidas todas aquelas questões "que concernem à relação com o saber, à economia do conhecimento e à relação das árvores do conhecimento com a democracia". Outro ensinamento de Lévy (1993, p. 195) é o de que, "quanto melhor compreendermos 'a essência da técnica', mais se tornará claro que há espaço para uma tecnodemocracia, que em amplo espaço permanece aberto à crítica e à intervenção, aqui e agora”.

\section{Notas}

1 Para se obter uma extensa descrição dos principais sistemas de gestão do conhecimento existentes (voltados para: a gestão de documentos e de conteúdo; taxonomia organizacional; serviços de colaboração; criação de dados e conhecimentos; redes de especialistas; portais de conhecimento; gestão de relacionamento com clientes; gestão de competências; e gestão de e-learning), ver Lindvall, Mikael; Rus, Ioana; e Sinha, Sachin Suman. Software systems support for knowledge management. Journal of Knowledge Management, vol. 7, n. 5, p. 137-150.

2 Para visualizar a estrela de diorito e o conteúdo das 282 cláusulas do Código de Leis de Hamurabi, visitar o website da Rede Direitos Humanos e Cultura. Disponível em: <http:/ /www.dhnet.org.br/direitos/ANTHIST/hamurabi.htm>. Acesso em: 22 dez. 2003. 
3 Para obter uma digitalização da Bíblia impressa por Gutenberg, visitar o website da The British Library. Disponível em: <http://prodigi.bl.uk/gutenbg/record.asp?strCopy=k\&str Page=1r1\&strSize=big $>$. Acesso em: 22 dez. 2003.

4 Paul Mauchly também foi o inventor do skateboard. Na Internet, pode ser visualizada uma prévia do documentário intitulado: "Mauchly: The Computer and the Skateboard". Disponível em: <http://www.blastoffmedia.com/mauchly/preview.htm>. Acesso em: 01 fev 2004.

5 Wenger, Etienne C. \& Snyder, W. M. Communities of Practice: The Organizational Frontier. Harvard Business Review, jan-fev 2000, p. 139-145.

6 Para saber mais sobre a economista Joan Violet Robinson (1903 - 1983), ler trabalho de Cláudia Heller, professora do Departamento de Economia da Faculdade de Ciências e Letras da UNESP, intitulado "Joan Robinson - Bibliografia ampliada". Disponível em: <http://www.race.nuca.ie.ufrj.br/revistas/socinfo/artigos/heller1.htm>. Acesso em: 02 fev 2004.

\section{Referências bibliográficas}

Adorno, Theodor W.; Horkheimer, Max. Dialética do Esclarecimento. Rio de Janeiro: Jorge Zahar Editor, 1985.

CAmpos, Vicente Falconi. TQC: gerenciamento da rotina do trabalho do dia-a-dia. Belo Horizonte: Fundação Christiano Ottoni, 1994.

Castells, Manuel. A sociedade em rede - A era da informação: economia, sociedade e cultura; v. 1. São Paulo: Paz e Terra, 1999.

CCMD Centro Canadense para o Desenvolvimento da Gestão. Canadá: organizações de aprendizagem no setor público. Revista do Serviço Público, Brasília, DF, ano 52, n.3, p. 101-122, jul.-set. 2001.

DAvenPort, Thomas H. e PRUSAK, Laurence. Conhecimento empresarial: como as organizações gerenciam seu capital intelectual. Rio de Janeiro: Campus, 1998.

Drucker, Peter. A sociedade pós-capitalista. São Paulo: Pioneira, 1993.

. Desafios gerenciais para o século XXI. São Paulo: Pioneira, 1999.

Huertas, Franco. O método PES: entrevista com Matus. São Paulo: FUNDAP, 1996.

KLEIN, David A. A gestão estratégica do capital intelectual: recursos para a economia baseado em conhecimento. Rio de Janeiro: Qualitymark, 1998.

LÉvy, Pierre. As tecnologias da inteligência: o futuro do pensamento na era da informática. Rio de Janeiro: Ed. 34, 1993.

LÉvy, Pierre e AuthiEr, Michel. As árvores de conhecimentos. São Paulo: Editora Escuta, 2000 .

NonaKa, Ikujiro e TAKEuCHI, Hirotaka. Criação de conhecimento na empresa. Rio de Janeiro: Campus, 1997.

SENGE, Peter. A quinta disciplina: arte e prática da organização que aprende. São Paulo: Best 
Senge, Peter. A dança das mudanças. Rio de Janeiro: Campus, 1999.

Stewart, Thomas A. Capital intelectual. Rio de Janeiro: Campus, 1998.

A riqueza do conhecimento: o capital intelectual e a nova organização do século XXI. Rio de Janeiro: Campus, 2002.

Sveıby, Karl Erik. A Nova Riqueza das Organizações. Rio de Janeiro: Campus, 1998.

TERRA, José Cláudio Cyrineu. Gestão do conhecimento: o grande desafio empresarial: uma abordagem baseada no aprendizado e na criatividade. São Paulo: Negócio Editora, 2001.

Terra, José Cláudio Cyrineu e Gordon, Cindy. Portais corporativos: a revolução na gestão do conhecimento. São Paulo: Negócio Editora, 2002. 
Revista do

Serviço

Público

Ano 55

Números 1 e 2

Jan-Jun 2004

Espartaco

Madureira

Coelho é

MBA em

Planejamento,

Orçamento e

Gestão Pública

pela FGV/DF,

Especialista

em Políticas

Públicas e

Gestão

Governamental

e assessor de TI

da Secretaria-

Executiva do

Ministério da

Educação.

Contato:

espartac@msn.com

\section{Abstract}

\section{Gestão do conhecimento como sistema de gestão para o setor público \\ Espartaco Madureira Coelho}

O conhecimento e a gestão do conhecimento têm sido focos de uma intensa discussão sobre como as organizações privadas podem obter vantagens competitivas e atingir elevados patamares de flexibilidade, produtividade e inovação, sem que, no entanto, esta disciplina seja devidamente debatida e/ou incorporada pelo setor público brasileiro.

A partir da perspectiva dos autores de maior prestígio no assunto, este trabalho apresenta os principais conceitos e aspectos relacionados a este novo paradigma de gestão organizacional, de modo a identificar quais seriam os principais desafios para a implantação de projetos de gestão do conhecimento no âmbito da administração pública.

Adicionalmente, este trabalho propõe a adoção de um novo modelo de gestão do conhecimento, mais consistente e adequado às organizações públicas.

O modelo de gestão apresentado propõe-se a servir como subsídio para um debate teórico e metodológico sobre como a gestão do conhecimento poderia ser incorporada à tarefa de buscar melhores níveis de gestão para as organizações públicas brasileiras, de forma a torná-las mais capacitadas a fazerem frente às interferências que já provocaram a falência das instâncias de planejamento e orçamento no setor público, o abandono da padronização e da melhoria dos procedimentos administrativos, a desestruturação da função pública e das políticas de recursos humanos, a persistente descontinuidade de projetos e de políticas públicas, assim como permita resgatar a credibilidade nos mecanismos internos de repressão e de punição àqueles agentes que adotam práticas ou condutas que vão de encontro aos princípios morais e às normas jurídicas estabelecidas.

\section{La gestión del conocimiento como sistema de gestión para el sector público Espartaco Madureira Coelho}

El conocimiento y la gestión del conocimiento han sido focos de una intensa discusión sobre cómo las organizaciones privadas pueden obtener ventajas competitivas y alcanzar elevados niveles de flexibilidad, productividad e innovación, sin que, sin embargo, esa disciplina sea debidamente debatida y/o incorporada por el sector público brasileño.

A partir de la perspectiva de los autores de más prestigio en el asunto, este trabajo presenta los principales conceptos y aspectos relacionados con este nuevo paradigma de gestión organizacional, de manera a identificar cuales serían los principales desafíos para la implantación de proyectos de gestión del conocimiento en el ámbito de la administración pública.

Adicionalmente, este trabajo propone la adopción de un nuevo modelo de gestión del conocimiento, más consistente y adecuado a las organizaciones públicas.

El modelo de gestión presentado se propone servir como subsidio para un debate teórico y metodológico sobre cómo la gestión del conocimiento podría incorporarse a la tarea de buscar mejores niveles de gestión para las organizaciones públicas brasileñas, de manera a volverlas más capaces de hacerles frente a las interferencias que ya han causado el fracaso de las instancias de planificación y presupuesto en el sector público, el abandono de la estandardización y la mejoría de los procedimientos administrativos, la de-estructuración de la función pública y de las políticas de recursos humanos, la persistente falta de continuidad de proyectos y de políticas públicas, y que permita rescatar la credibilidad de los mecanismos internos de represión y de punición de aquellos agentes que adoptan prácticas o conductas que entran en conflicto con los principios morales y las normas jurídicas establecidas. 


\section{Knowledge management as a management system for the public sector Espartaco Madureira Coelho}

Knowledge and knowledge management have been the focal points of an intense discussion on how private organisations can obtain competitive advantages and attain high thresholds of flexibility, productivity and innovation, without, however, this discipline having being duly debated and/or incorporated by the brazilian public sector.

Starting from the perspective of the most prestigious authors who have written on the matter, this work presents the main concepts and aspects pertaining to this new paradigm of organisational management, in order to identify which would be the major challenges in view of putting in place knowledge management projects within public administration.

In addition, this work proposes the adoption of a new model of knowledge management that is more consistent and adapted to public organisations.

The management model presented is aimed at informing a theoretical and methodological debate on how knowledge management might be incorporated to the task of seeking better levels of management for brazilian public organisations, in order to better equip them to face the interferences that have already brought about the failure of planning and budgeting decision-making levels in the public sector. It is also aimed at the abandonment of standardisation and at the improvement of administrative procedures, at the destructuring of public service and of human-resource policies, as well as at tackling the persistent discontinuity of projects and public policies, and at redeeming the credibility of internal mechanisms of repression and punishment applied to those agents who adopt practices or behaviours that conflict with moral tenets and established legal norms. 